\title{
BIOTV INTERATIVA: CONSTRUINDO AQUÁRIOS SUSTENTÁVEIS COMO FERRAMENTA DE EDUCAÇÃO AMBIENTAL
}

\author{
Simone Wellita Simão de Carvalho ${ }^{1}$ \\ Thiago Bernardo de Souza ${ }^{2}$ \\ Leonardo dos Reis Periard ${ }^{3}$ \\ Jéferson Luiz Ferrari ${ }^{4}$ \\ Marcos Antônio Sattler ${ }^{5}$
}

Resumo: A produção de lixo eletrônico tem se destacado mundialmente entre os maiores geradores de resíduos da atualidade, além de serem descartados de forma inadequada, impactando o ambiente e a saúde pública, pois apresentam em sua composição diversos metais pesados. O presente trabalho teve como objetivo a produção de BioTv's interativas (aquários sustentáveis), por meio da reciclagem do lixo eletrônico (televisores, gabinetes, monitores de computadores) e de rejeitos de pisos cerâmicos, de forma integrada com a comunidade e estudantes, construindo uma ferramenta de Educação Ambiental, sendo posteriormente destinadas as instituições parceiras com intuito de trabalhar a interdisciplinaridade, em prol do desenvolvimento sustentável.

Palavras-chave: Reciclagem. Lixo Eletrônico. Desenvolvimento Sustentável.

\footnotetext{
${ }^{1}$ Instituto Federal do Espírito Santo, Campus de Alegre, ES. E-mail: simonewellita@gmail.com

2 Instituto Federal do Espírito Santo, Campus de Alegre, ES. E-mail: thiagoaquicultura@gmail.com

${ }^{3}$ Instituto Federal do Espírito Santo, Campus de Alegre, ES. E-mail: leozinho.periard@gmail.com

${ }^{4}$ Instituto Federal do Espírito Santo, Campus de Alegre, ES. E-mail: ferrarijluiz@gmail.com

${ }^{5}$ Instituto Federal do Espírito Santo, Campus de Alegre, ES. E-mail: masattler@ifes.edu.br
} 


\section{Introdução}

Segundo Baldé et al. (2017), a produção mundial de lixo eletrônico no ano de 2016 atingiu aproximadamente 44,7 milhões de toneladas, o que equivale a $6,1 \mathrm{~kg}$ por habitante. Desse total, 11,3 toneladas correspondem a produção anual das américas, sendo que apenas 2 toneladas desse material foi coletado e reciclado por meio de documentação específica. Ainda segundo Baldé et al. (2017), o Brasil é o segundo maior produtor de lixo eletrônico das américas, com uma produção anual que equivale a 1,5 tonelada, ficando atrás apenas dos Estados Unidos da América, o qual apresenta uma produção de 6,3 milhões de toneladas.

A maior parte dos resíduos gerados são provenientes de alguns setores da indústria de informática e com relação a esse tema, Mattos e Perales (2008) ressaltam ainda que este setor não era visto como grande poluidor, porém, devido aos avanços tecnológicos desordenados, acabou gerando produtos obsoletos, resultando numa quantidade de lixo tecnológico. Mattos e Perales (2008) afirmam ainda que, devido à ausência de planejamento, ocasionou um elevado índice no descarte inadequado por parte da sociedade, a qual atualmente busca um elo entre o consumo e o descarte. Dentre desse contexto, pode-se destacar os resíduos de equipamentos elétricos/eletrônicos, popularmente chamado de lixo eletrônico ou e-lixo.

Mucelin e Bellini (2008) relatam que é comum observar os hábitos de descarte inadequado de lixo, sendo esses resíduos descartados de forma irregular no ambiente, e jogados em locais indevidos como por exemplo, nos lotes baldios, nas margens de estradas e rodovias, nos fundos de vale e próximo de lagos e rios, gerando maiores riscos para a população.

Sobre os resíduos eletrônicos, Guerin (2008, apud NATUME, 2011) declara que "Lixo eletrônico é o nome dado aos resíduos da rápida obsolescência de equipamentos eletrônicos, que incluem computadores e eletrodomésticos, entre outros dispositivos". Com relação aos efeitos negativos causados pelo descarte inadequado desses equipamentos, Mattos e Perales (2008) dizem que grande parte dos componentes presentes nesses materiais apresentam em sua composição substâncias químicas, como por exemplo, o cobre, chumbo, cádmio, mercúrio, alumínio e arsênio, que podem prejudicar tanto a saúde humana como o meio ambiente, por meio da penetração no solo, atingindo o lençol freático contaminando animais e vegetais por meio da água.

Como visto, essa grande demanda de equipamentos eletrônicos pode ocasionar prejuízos significativos ao meio ambiente caso seja descartado de forma inconsciente, acarretando uma série de alterações ambientais.

A grande exploração dos recursos naturais com o passar dos anos vem aumentando gradativamente. Paralelo a ela a geração de resíduos tem se tornado maior do que a capacidade de renovação natural, e o destino desses materiais têm sido um agravante para o meio ambiente. 
Para minimizar o impacto gerado pelo descarte indevido do lixo eletrônico, a Política Nacional de Resíduos Sólidos (PNRS), aprovada em 2010, por meio da Lei 12.305 (BRASIL, 2010) visa estabelecer normas preventivas para evitar e diminuir a elevada quantidade de resíduos eletroeletrônicos que seriam descartados de forma inadequada no ambiente, designando a responsabilidade compartilhada entre as diversas categorias da sociedade. E declara a logística reversa, obrigando fabricantes, importadores, distribuidores e vendedores a criar mecanismos para recolher estes produtos após seu tempo de vida útil, dando a eles a destinação adequada.

De acordo com a Lei 12.305/2010, a destinação final ambientalmente correta se dará por meio de reciclagem, reutilização, recuperação, compostagem, e outras destinações admitidas pelos órgãos competentes.

Neste contexto, cabe ressaltar a importância da Educação Ambiental, conforme asseveram Sales e Dias (2013), quando dizem que ela pode ser usada como um instrumento de cidadania, pois possui um papel indispensável perante a sociedade, passando a ser uma necessidade social e cultural, pelo fato de contribuir para a formação de cidadãos éticos, a fim de disseminar a importância da conscientização sobre a sustentabilidade, incentivando a adoção de práticas ecologicamente corretas, garantindo a preservação do planeta para as gerações futuras. De acordo com a Política Nacional de Educação Ambiental, no Brasil:

Os processos por meio dos quais o indivíduo e a coletividade constroem valores sociais, conhecimento, habilidades, atitudes e competências voltadas para a conservação do meio ambiente, bem de uso comum do povo, essencial à sadia qualidade de vida e sua sustentabilidade é através da Educação Ambiental, sendo ela um componente essencial e permanente da educação nacional, devendo estar presente de forma articulada, em todos os níveis e modalidades do processo educativo, em caráter formal e não formal (BRASIL, 1999).

Diante desta reflexão, Sales e Dias (2013) expõem que o ambiente escolar apresenta uma responsabilidade fundamental na formação dos alunos como cidadãos, contribuindo para a formação de pessoas críticas e engajadas com seus direitos e deveres. Para tal, diversas ferramentas didáticopedagógicos se prestam como instrumentos, com o intuito de fortalecer os saberes ambientais como primordiais.

Pensando na Educação Ambiental como prática pedagógica, somando sua ação à integração universidade e comunidade, algumas ferramentas podem ser utilizadas para o engajamento desta prática pedagógica. Pode-se citar como exemplo a implantação de trabalhos de extensão comunitária, a qual se baseia em atividades práticas e lúdicas em busca de um tema específico, 
contribuindo para o progresso da sociedade, além de colaborar para o crescimento pessoal e profissional de alunos e professores envolvidos.

Entretanto, Mendonça e Silva, (2002) afirmam que poucos são os que têm acesso direto aos conhecimentos gerados na universidade pública. Sendo que a extensão universitária é imprescindível para a democratização do acesso a esses conhecimentos, assim como para o redimensionamento da função social da própria universidade, principalmente se for pública. Mendonça e Silva (2002) ressaltam que, uma das principais funções sociais da universidade é contribuir na busca de soluções para os graves problemas sociais da população, formulando políticas públicas participativas e emancipadoras.

Para Menezes et al. (2011) o uso de novas metodologias motivadoras facilita aos alunos desenvolver habilidades e pensamento crítico. Novas estratégias, difundem a interdisciplinaridade, e é fazendo uso de recursos didáticos inovadores que é possível proporcionar aos alunos aulas dinâmicas e expositivas. Menezes et al. (2011) afirma ainda que o uso de aquários como pequeno ecossistema proporciona aos professores trabalhar diversas áreas, dentro dos conteúdos programados, atuando como uma ferramenta didática. Corroborando com isso Corradini (2007) aponta que, a partir de um ecossistema artificial desenvolvido dentro da sala de aula, é possível integrar diversas disciplinas, possibilitando a demonstração dos seres vivos ali presente, de forma a apresentar a relação entre os organismos e o meio em que está inserido e os comportamentos apresentados e ainda desenvolver atividades como montagem e manutenção de aquários.

Como ressaltado por Oliveira et al. (2013) o uso de aquários no ambiente escolar é capaz de sensibilizar e conscientizar os estudantes sobre a necessidade da conservação dos ecossistemas naturais e assim despertar para os problemas ambientais quando se introduz uma espécie exótica em determinado ambiente, os cuidados com o uso da água, entre diversos fatores que poderão ser trabalhados, bem como elencar a Educação Ambiental com novas perspectivas pedagógicas a partir da junção de ambas as partes afim de contribuir para o conhecimento dos alunos.

A partir dos diagnósticos preocupantes em relação a alta produção de lixo eletrônico, acarretando a poluição do planeta, a Educação Ambiental passa a ter um papel fundamental na vida da sociedade, a qual deve se manter comprometida com a responsabilidade de conservação e preservação do meio ambiente. Para atender aos objetivos desta pesquisa, e fomentar as práticas conservacionistas e sensibilizadoras, buscou-se construir aquários sustentáveis a partir de materiais recicláveis, com a intenção de minimizar a problemática do lixo eletrônico gerado nos municípios de Alegre e Jerônimo Monteiro, ES, Brasil, após perceber o quanto a população sofre de maneira direta e indireta pela falta de informação a respeito do descarte adequado.

Diante dessa problemática, a BioTv Interativa, onde, Bio $=$ vida, $T v=$ televisores e Interativa = produto que visa promover a interação dos envolvidos, foi elaborada para a trabalhar a Educação Ambiental de forma 
integrada - Ifes x Escolas e/ou instituições x Comunidade, sendo a principal ação educativa a utilização do lixo eletrônico como matéria-prima para confecção de aquários sustentáveis reaproveitando televisores, monitores de computadores e gabinetes que seriam descartados incorretamente. Após a confecção, os aquários foram destinados para a Escola Municipal de Ensino Fundamental Paulo Pereira Gomes, localizada no município de Jerônimo Monteiro, como ferramenta de Educação Ambiental, de forma a conectar os envolvidos com o ambiente.

Conforme exposto, o presente trabalho tem por finalidade produzir aquários sustentáveis, através da reciclagem do lixo eletrônico e de restos de pisos cerâmicos, de forma conjunta com estudantes e a comunidade, dando origem a uma ferramenta de Educação Ambiental, com o intuito de conectar as pessoas ao ambiente onde pertencem.

\section{Legislação mundial e brasileira sobre o meio ambiente}

A Conferência de Estocolmo foi a $1^{\text {a }}$ Conferência das Nações Unidas sobre Ambiente Humano, sediada na cidade de Estocolmo - Suécia, em 1972, que reuniu os países de terceiro mundo com o objetivo mobilizar e construir alternativas para a proteção ambiental com o cuidado de não trazer prejuízos ao crescimento econômico para esses países. Após a Conferência, o governo brasileiro deu início a elaboração de Leis para preservação ambiental no país. Uma delas encontra-se no art. o da Lei Federal oㅜ 6.938 (BRASIL, 1981) descrevendo que a Política Nacional do Meio Ambiente tem por objetivo a melhoria e recuperação da qualidade ambiental propícia à vida, visando assegurar no país, condições ao desenvolvimento socioeconômico, aos interesses da segurança nacional e à proteção da dignidade da vida humana [...].(BRASIL, 1981, apud MOREIRA, 2014).

Para regulamentar a questão do lixo tecnológico, em 1989 foi a criada a Convenção da Basiléia. Segundo Mattar (2002) a Convenção de Basiléia é o documento que mais chega perto de regulamentar o lixo eletrônico ao estabelecer um regime internacional de controle e cooperação - cujo objetivo é incentivar a minimização da geração de resíduos perigosos (com mudanças nos próprios processos produtivos) e reduzir o movimento desses resíduos nas fronteiras. A Convenção é o único tratado internacional que pretende monitorar inclusive o impacto ambiental das operações de depósito, recuperação e reciclagem que se seguem ao movimento de transporte destes resíduos perigosos. O documento estabelece, por exemplo, o consentimento prévio, por escrito, por parte dos países importadores para os resíduos especificados para importação; adoção de medidas adequadas de minimização da geração de resíduo; e administração ambientalmente correta de resíduos e seu depósito.

Devido a grande preocupação com a preservação dos recursos naturais e a crescente produção de resíduos sólidos no Brasil, em agosto de 2010 foi sancionada a Política Nacional de Resíduos Sólidos (PNRS), a qual 
agrega um conjunto de ações e diretrizes a serem seguidas para que a gestão destes resíduos seja realizada de forma funcional.

A PNRS em seu art. $1^{\circ}$ declara que

os princípios, objetivos e instrumentos, bem como sobre as diretrizes relativas à gestão integrada e ao gerenciamento de resíduos sólidos, incluídos os perigosos, são de responsabilidade dos geradores e do poder público e aos instrumentos econômicos aplicáveis.

Diante de suas definições, no art. $3^{\circ}$ inciso VII, entende-se por destinação final ambientalmente adequada a

destinação de resíduos que inclui a reutilização, a reciclagem, a compostagem, a recuperação e o aproveitamento energético ou outras destinações admitidas pelos órgãos competentes do Sistema Nacional do Meio Ambiente (Sisnama), do Sistema Nacional da Vigilância Sanitária (SNVS) e do Sistema Unificado de Atenção à Sanidade Agropecuária (Suasa), entre elas a disposição final, observando normas operacionais específicas de modo a evitar danos ou riscos à saúde pública e à segurança e a minimizar os impactos ambientais adversos (BRASIL, 2010).

Cabe ressaltar que desde a Conferência das Nações Unidas para o Meio Ambiente e o Desenvolvimento (CNUMAD) - RIO-92 que ocorreu no Brasil, iniciou-se uma preocupação em relação a consciência ambiental, onde os governos passaram a perceber a necessidade de desenvolver medidas preventivas para tratar das questões ambientais.

Portanto, a logística reversa surge para estabelecer essas medidas e de certa forma, tentar evitar e minimizar a quantidade significativa de resíduos eletrônicos descartados no meio ambiente.

De acordo com a PNRS, no inciso XII, logística reversa é definida como

\begin{abstract}
instrumento de desenvolvimento econômico e social caracterizado por um conjunto de ações, procedimentos e meios destinados a viabilizar a coleta e restituição dos resíduos sólidos ao setor empresarial, para reaproveitamento, em seu ciclo ou em outros ciclos produtivos, ou outra destinação final ambientalmente adequada (BRASIL, 2010).
\end{abstract}

A PNRS estabelece ainda a responsabilidade compartilhada entre o consumidor, comerciantes, fabricantes e importadores em dar a esse material após seu tempo de vida útil, a destinação ambientalmente adequada. Definindo como resíduos sólidos 
material, substância, objeto ou bem descartado resultante de atividades humanas em sociedade, cuja destinação final se procede, se propõe proceder ou se está obrigado a proceder, nos estados sólido ou semissólido, bem como gases contidos em recipientes e líquidos cujas particularidades tornem inviável o seu lançamento na rede pública de esgotos ou em corpos d'água, ou exijam para isso soluções técnica ou economicamente inviáveis em face da melhor tecnologia disponível.

Devido aos inúmeros problemas ambientais causados pelo lixo eletrônico, é fundamental que medidas sustentáveis sejam realizadas para a prevenção deste problema. A Lei $n^{\circ} 12.305 / 2010$, no Art. $30^{\circ}$ preconiza que

a responsabilidade é compartilhada pelo ciclo de vida dos produtos, a ser implementada de forma individualizada e encadeada, abrangendo os fabricantes, importadores, distribuidores e comerciantes, os consumidores e os titulares dos serviços públicos de limpeza urbana e de manejo de resíduos sólidos, consoante às atribuições e procedimentos previstos nesta seção (BRASIL, 2010).

\section{Lixo eletrônico: Meio ambiente e saúde humana}

De acordo com Miguez (2010, apud GAMA et al., 2016, p.1) "os produtos eletrônicos contêm uma grande quantidade de substâncias danosas ao ambiente. Este fato faz com que estes produtos não possam ser descartados em aterros sanitários comuns". Uma placa de circuito interno, por exemplo, possui chumbo, cromo, cádmio e estanho. Entre os mais perigosos estão o mercúrio, o cádmio (encontrado em baterias de celulares).

Segundo Valentim et al. (2015) e Silva (2010), os componentes do lixo eletrônico podem desencadear alguns problemas ao meio ambiente e saúde humana.

De acordo com Gonçalves (2007) os metais pesados podem desencadear alguns danos para o homem e o meio ambiente, conforme apresentado o Quadro 1. 
Quadro 1: Danos provocados por metais pesados ao meio ambiente e a saúde humana.

\begin{tabular}{|c|l|}
\hline COMPONENTE & \multicolumn{1}{|c|}{ DANOS PROVOCADOS } \\
\hline Chumbo & $\begin{array}{l}\text { Causa danos aos sistemas nervoso e sanguíneo. O acúmulo no meio } \\
\text { ambiente, apresenta efeitos tóxicos, agudos e crônicos em vegetais e } \\
\text { animais. }\end{array}$ \\
\hline Cádmio & $\begin{array}{l}\text { Acumula-se nos rins, fígados e ossos, é absorvido através da } \\
\text { respiração e alimentação. Apresenta um grande perigo ao meio } \\
\text { ambiente devido a sua alta toxicidade e seus efeitos acumulativos. }\end{array}$ \\
\hline Mercúrio & $\begin{array}{l}\text { Causa danos ao cérebro e ao fígado, substância bioacumulativa que se } \\
\text { concentra através da cadeia alimentar. }\end{array}$ \\
\hline Níquel & Acarreta danos ao fígado, sistema sanguíneo e pulmões. \\
\hline Arsênio & Atinge aos sistemas respiratório, cardiovascular e nervoso. \\
\hline
\end{tabular}

Fonte: Adaptado de Gonçalves (2007)

Outra substância muito utilizada na produção de equipamentos eletrônico é o plástico, apesar de muitas empresas fabricantes já terem reduzido o seu uso, ainda há um volume considerável de PVC contido em restos de equipamentos, o qual demora centenas de anos para se decompor no meio ambiente. Sendo uma crescente preocupação o descarte dessas substâncias em aterros sanitários, pois o país possui muitos aterros antigos, e até mesmo os mais modernos nos dias atuais, estão sujeitos ao risco de vazamento, de produtos químicos e metais, o que poderá infiltrar no solo. Esta situação é muito pior em aterros sanitários velhos e menos controlados, que acabam sendo a maioria em todo país (GONÇALVES, 2007 apud VALENTIM et al., 2015).

Valentim et al. (2015) afirmam que os principais problemas que podem ser causados pelo lixo eletrônico nos aterros sanitários, é que após a destruição de um equipamento eletrônico, como por exemplo, um interruptor de circuito, poderá ocorrer o vazamento do mercúrio e do cádmio sendo esses metais pesados capaz de infiltrar no solo contaminando os lençóis freáticos, causando diversos danos ambientais e sociais. Um outro problema está relacionado com a quantidade de íons de chumbo presente em um vidro cônico dos tubos de raios catódicos que podem ser dissolvidos no meio ambiente.

Tanaue et al. (2015) ressaltam ainda que existem três maneiras para a destinação correta do lixo eletroeletrônico. A primeira está relacionada aos equipamentos que ainda possuem algum tempo de vida, esses poderiam ser utilizados pela comunidade em projetos de inclusão digital. A segunda está voltada para 0 descarte das partes que são obsoletas, que podem ter seus componentes reutilizados e reciclados. A terceira, e não menos importante, seria a sensibilização da população por meios de palestras, criação de postos de coletas, visando à importância da reciclagem do lixo eletrônico para a sustentabilidade do seu ciclo de consumo. 


\section{A Educação Ambiental de forma integrada com a comunidade}

Segundo a Lei $n^{\circ}$ 9.795/1999 (BRASIL/1999), todos têm direito à Educação Ambiental, sendo ela um componente essencial e permanente da educação nacional, a qual deverá estar presente em todos os níveis e modalidades do processo educativo, seja de caráter formal ou não-formal.

A Educação Ambiental é um tema que deve ser compreendido de forma integrada, abrangendo a prática pedagógica e a representatividade social.

De acordo com Assano e Poletto (2017, p. 92):

Os trabalhos relacionados à Educação Ambiental na escola devem ter como objetivos: a sensibilização e a conscientização; os conteúdos ambientais devem permear todas as disciplinas do currículo e serem contextualizados com a realidade da comunidade, a escola ajudará o aluno a perceber a correlação dos fatos e a ter uma visão integral do mundo em que vive. Para isso, a Educação Ambiental deve ser abordada de forma sistemática e transversal, em todos os níveis de ensino, assegurando a presença da dimensão ambiental de forma interdisciplinar nos currículos das diversas disciplinas e das atividades escolares.

Fundamentando a premissa de que atualmente os indivíduos devem se sentir integrantes do processo na busca para minimizar os problemas ambientais. E para que seja eficiente, é fundamental que comunidade e a escola ajam em conjunto.

\section{A Importância da educação não formal}

A educação não formal tem se destacado nos últimos anos surgindo com o intuito de minimizar as falhas geradas pelo sistema de educação formal, na busca para o aperfeiçoamento dos métodos de ensino e aprendizagem. A esse respeito, Gadotti (2012, p. 10) aponta que:

A educação formal é representada principalmente pelas escolas e universidades. Ela depende de uma diretriz educacional centralizada como o currículo, com estruturas hierárquicas e burocráticas, determinadas em nível nacional, com órgãos fiscalizadores do Ministério da Educação. A educação não-formal é mais difusa, menos hierárquica e menos burocrática. Os programas de educação não-formal não precisam necessariamente seguir um sistema sequencial e hierárquico de "progressão". Podem ter duração variável, e podem, ou não, conceder certificados de aprendizagem. 
Gadotti (2012) aponta ainda que a educação não formal é uma atividade educacional a ser realizada fora do ambiente formal. Funcionando de forma sistematizada e organizada, caracterizando a flexibilidade de tempo e espaço, respeitando as diferenças e capacidade de cada indivíduo, desenvolvendo suas potencialidades.

Não existe apenas uma maneira correta de se fazer educação, e essa afirmativa serve tanto para a formal, quanto para a não formal. O que se deve priorizar, no entanto, é o aprendizado. Em se tratando de meio ambiente, e a maneira como ele é entendido, a Educação Ambiental ganha espaço e se concretiza através de ações dentro e fora da sala de aula. No entanto, ela passa por grandes provocações e a esse respeito, Jacobi (2003) afirma que um dos grandes desafios da Educação Ambiental é se formular para que seja crítica e inovadora, a nível formal e não formal. Para que dessa forma a Educação Ambiental esteja voltada para a transformação social, com foco no homem, natureza e universo, levando em consideração que os recursos naturais irão se esgotar e que o principal responsável pela sua degradação é próprio homem.

Segundo Gohn (2010):

A educação não-formal designa um processo com várias dimensões tais como: a aprendizagem e exercício de práticas que capacitam os indivíduos a se organizarem com objetivos comunitários, voltadas para a solução de problemas coletivos cotidianos; a aprendizagem de conteúdos que possibilitem aos indivíduos fazerem uma leitura do mundo do ponto de vista de compreensão do que se passa ao seu redor.

É partindo desse pressuposto que práticas ambientais são desenvolvidas, disseminando a Educação Ambiental, buscando uma relação do indivíduo com o meio em que se está inserindo, de forma a minimizar os impactos deixados pela falta de conscientização e de responsabilidade com o meio em que se vive.

\section{Materiais e Métodos}

O estudo foi realizado nos municípios de Alegre (distrito de Rive) e Jerônimo Monteiro, no Sul do estado do Espírito Santo, envolvendo o Instituto Federal do Espirito Santo - Ifes/Campus de Alegre; a Escola Municipal de Ensino Fundamental Paulo Pereira Gomes e a comunidade, de forma a trabalhar a Educação Ambiental de maneira interativa (Figura 1). 


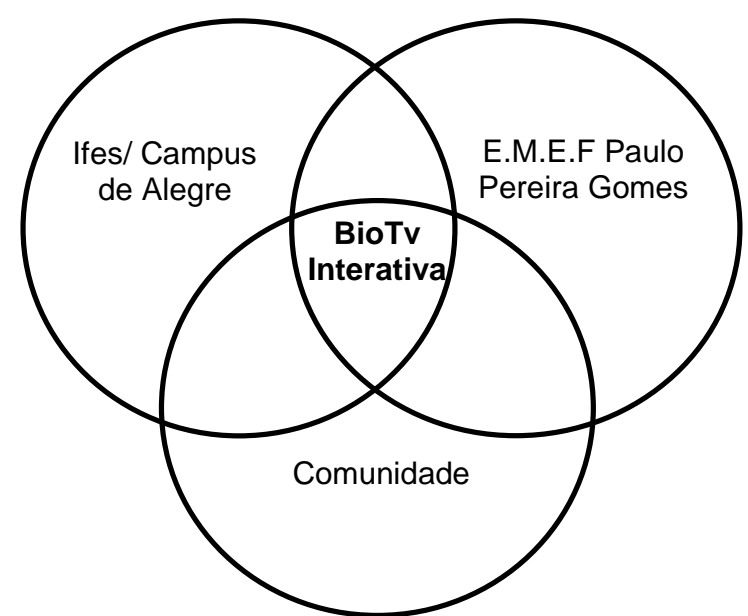

Figura 1: Contexto de atuação do Projeto BioTv Interativa. Fonte: Elaborado pelos autores.

Foram feitas algumas incursões juntamente com estudantes de ambas as instituições, verificando como está acontecendo o descarte de lixo eletrônico em diversos locais nos Municípios, aproveitando a oportunidade de aprendizado em espaços não formais de educação, bem como trabalhar a proposição de resolução para os desafios encontrados, além de realizar a coleta desses materiais. Para conectar o Projeto com a comunidade, foi elaborada uma página no Facebook (BioTv Interativa) de forma a se comunicar com a população, agendar o recolhimento de lixo eletrônico nas residências, bem como divulgar todas as ações realizadas, ressaltando a importância de todos nas atividades desenvolvidas.

Posteriormente, foram agendadas coletas dos equipamentos, sendo transportados para o Laboratório de Tecnologia Aquícola Sustentável (LABTAS) do Ifes/Campus de Alegre e desmontados por profissionais da Tecnologia de Informação (TI), Estudantes do curso de Engenharia de Aquicultura e Ciências Biológicas, onde se retirou todos os parafusos externos e separando a carcaça da composição restante, como fios, tela, tubo de imagens, ou seja, toda estrutura interna do equipamento, conforme apresenta a Figura 2 (próxima página).

Após separar as partes internas para o descarte adequado, reservou-se a carcaça do equipamento eletrônico para iniciar a preparação dos aquários sustentáveis. Posteriormente foi realizado a medição da parte interna de cada equipamento (altura, largura e comprimento), sendo as medidas efetuadas de acordo com cada equipamento. Com o uso de Equipamentos de Proteção Individual (EPI's), e com o auxílio de uma máquina de cortar piso, foi feita uma abertura na parte superior da carcaça, para manutenção e ornamentação interna do aquário. E com o auxílio de uma furadeira, foi produzida uma abertura para facilitar a alimentação dos peixes. 


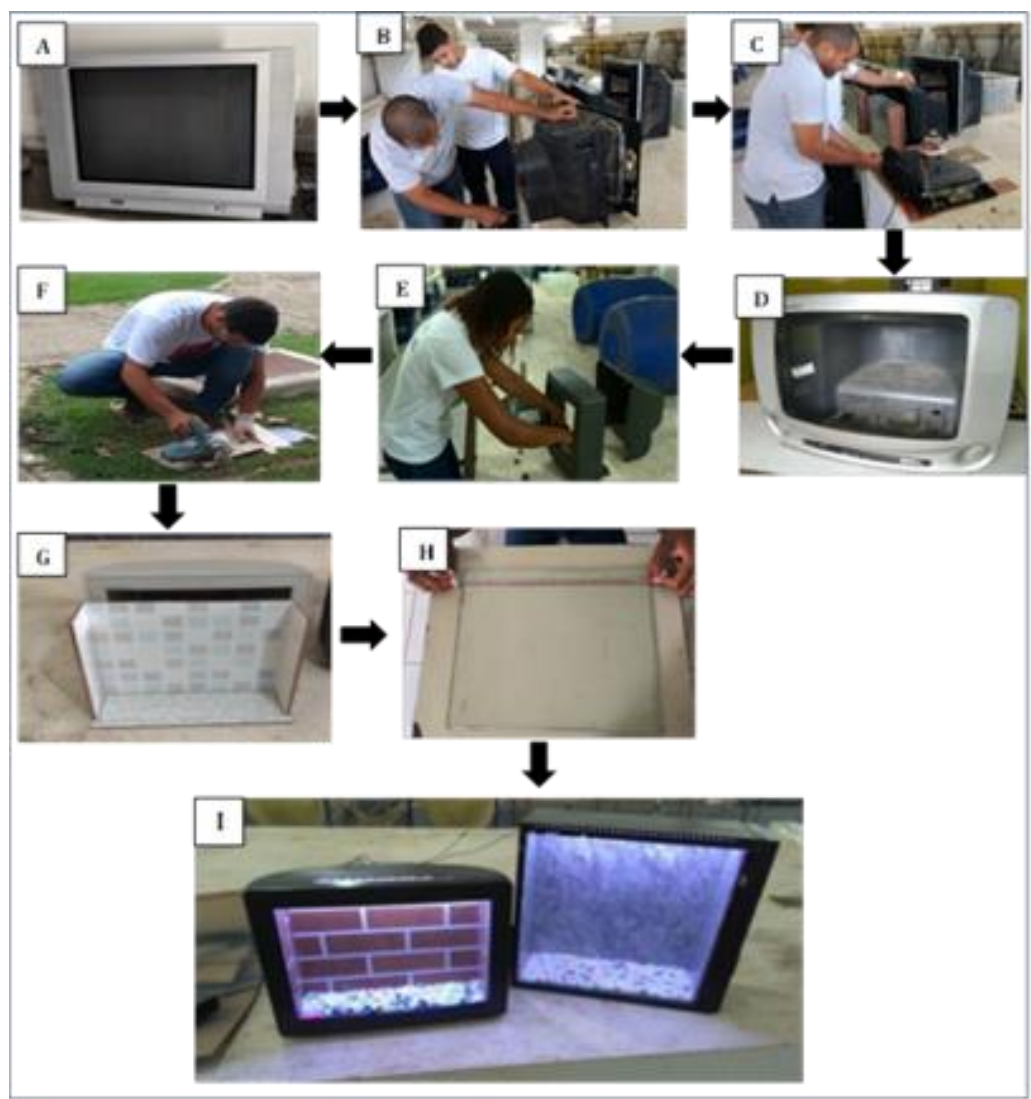

Figura 2: Sistema de Produção da BioTv Interativa. A - Lixo eletrônico; B - Desmontagem da Tv; C - Carcaça preparada; D - Separação do Tubo de Imagem; E - Retirada das dimensões do aparelho; F - Corte dos Pisos cerâmicos; G - Colagem dos pisos Cerâmicos; H - Medição e Colagem do Vidro; I - BioTv Interativa. Fonte: Elaborado pelos autores.

Em seguida foram delimitadas as medidas nos pisos cerâmicos com o auxílio de um esquadro para elaboração das partes que compõem a estrutura do aquário (base, painéis laterais e o painel traseiro), e com a utilização da máquina de cortar pisos, realizar os cortes. Para o painel dianteiro utilizou-se uma peça de vidro correspondente a medida da parte frontal do equipamento eletrônico.

Para montar a estrutura principal da BioTv, o primeiro passo a ser feito é a junção da base e painel traseiro. Antes de fixar as próximas partes, faz-se necessário esperar pelo menos 12 horas para anexar os painéis laterais. As partes são conectadas com auxílio da pistola de calafetagem usando silicone para vedação, com ação fixadora. Após esta etapa, o vidro é fixado e vedado às partes anteriores.

$\mathrm{Na}$ sequência, parte das Bio Tv's foram transferidas para a Escola Municipal Paulo Pereira Gomes e outra permaneceu no Instituto, onde os estudantes e servidores de ambas a instituições, ornamentaram os aquários sustentáveis, inserindo pedras ornamentais, conchas e as espécies de peixes ornamentais, finalizando o processo de produção da BioTv Interativa, para em seguida ser instalado nas salas de aula, permitindo aos professores trabalhar a interdisciplinaridade e multidisciplinaridade, conectando e integrando os estudantes com o ambiente e a resolução de problemas. 
Para analisar a viabilidade técnica da Bio Tv, foi utilizado o manual Alcon Pet (2018), o qual afirma existir uma grande variedade de aquários, confeccionados em diversas formas e tamanhos. O que garante a durabilidade do aquário é a forma como este foi colado, e é indispensável realizar o teste para detectar possíveis vazamentos, evitando assim problemas futuros.

Para Fujimoto et al. (2014), alguns procedimentos devem ser seguidos para construção de aquários com pisos cerâmicos. Para dar início ao processo de montagem, utilizou-se de quatro peças de piso e uma peça de vidro na mesma medida, e inicialmente deve-se colocar uma das peças em uma superfície plana, aplicar o silicone nas laterais das outras peças e uni-las, sendo a última etapa a fixar a peça de vidro e realizar o acabamento reforçando o fechamento de todas as partes com o silicone. Para avaliar a efetividade das ações de Educação Ambiental, foi adotado o método de observação direta que segundo

Lakatos e Marconi (1992), que apresenta um tipo de análise que "utiliza os sentidos na obtenção de determinados pontos da realidade. Não consiste apenas em ver e ouvir, mas também examinar fatos ou fenômenos que se deseja estudar".

Ações de Educação Ambiental foram desenvolvidas ao longo do trabalho, com intuito de interagir o Ifes, a escola municipal e a comunidade em geral, em prol de um objetivo em comum, buscando minimizar a problemática dos resíduos sólidos nos municípios abrangentes.

\section{Resultados e Discussão}

\section{Identificação do Descarte Inadequado}

Foram mapeados diversos pontos de descarte incorreto de lixo eletrônico nos municípios de Jerônimo Monteiro e Alegre, que ofereciam risco de contaminação (Figura 3).
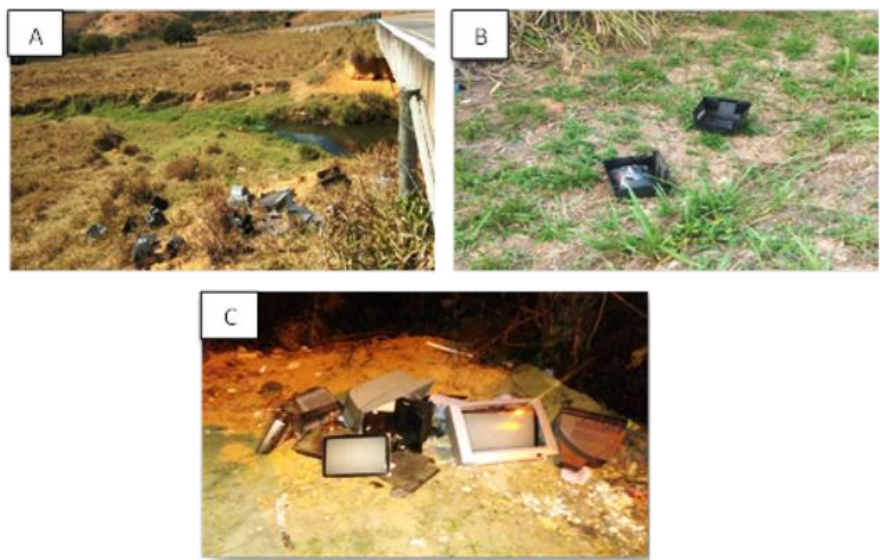

Figura 3: Descarte inadequado de lixo eletrônico. A e B, Rodovia ES 177 e C Rodovia 482.

Fonte: Elaborado pelos autores 
De acordo com Tanaue et al. (2015), quando a população descarta o lixo eletrônico sem dar a eles destinação correta, as substâncias químicas presentes nesses materiais podem contaminar o solo e atingir o lençol freático, e em contato com os lençóis freáticos, essas substâncias contendo metais pesados como ouro, prata, gálio, mercúrio, arsênico, cádmio, chumbo, berílio entre outros, contaminam a água a ser utilizada para rebanhos, irrigar plantações e consequentemente contaminar o homem através da alimentação, ocorrendo o processo de bioacumulação e biomagnificação.

Segundo Brasil (2010), os equipamentos eletrônicos devem ter uma destinação ambientalmente correta, seja esta por meio da reciclagem reutilização outras destinações permitidas pelos órgãos responsáveis, sendo essas destinações finais de responsabilidade de todos os membros da sociedade desde fabricantes, importadores, distribuidores, comerciantes e consumidores, os quais juntamente com instituições públicas e privadas devem desenvolver meios para que esses materiais não sejam descartados em locais impróprios.

\section{Coleta de lixo eletrônico no meio ambiente e na comunidade.}

Aconteceram diversas coletas de lixo eletrônico próximo as nascentes e nas margens de rios, envolvendo servidores e estudantes de ambas as instituições, promovendo uma relação de ensino $x$ aprendizagem em diversos níveis de ensino e de forma paralela em espaços não formais. Além disso, os moradores entraram em contato via página do projeto no Facebook, para realizar a doação do lixo eletrônico, e contribuindo com o descarte correto dos materiais (Figura 4). Ao todo, foram recolhidas 50 unidades de lixo eletrônico.
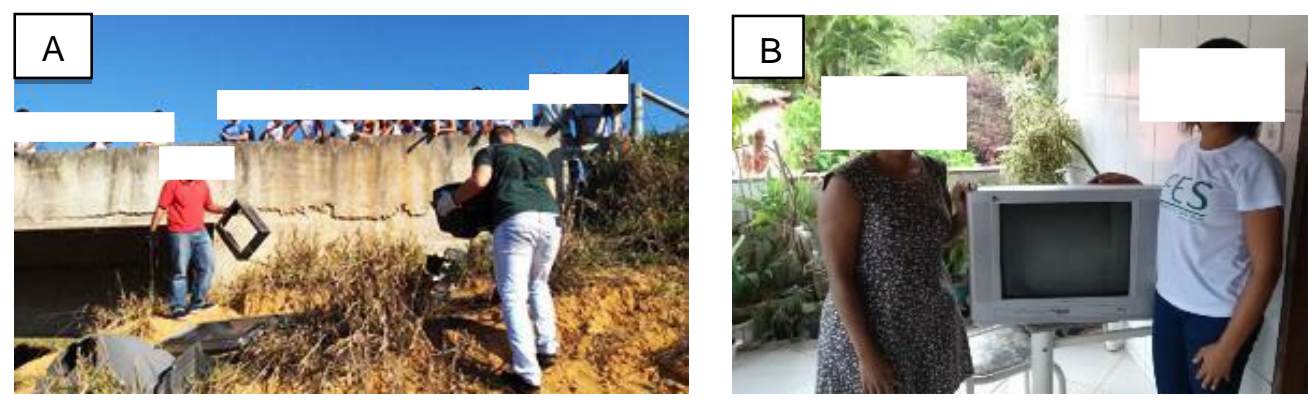

Figura 4: A - Coleta de lixo eletrônico nas margens do Córrego Aliança na Rodovia ES 177 e B

- Recebimento do lixo eletrônico doado pela comunidade. Fonte: Elaborado pelos autores

Em relação às coletas, as funções de limpeza de lixo são de responsabilidade da administração pública, porém, a população deve ter consciência da importância da destinação correta dos resíduos sólidos e dos benefícios que a referida ação gera para a própria comunidade, para a sua cidade e para o meio ambiente (FERREIRA, 2000 apud PROCHNOW, et al.2010). 
É importante ressaltar, que a participação da comunidade foi fundamental para o adequado desenvolvido do projeto, onde os moradores entraram em contato com a equipe responsável pelo trabalho, a fim de doar televisores que estavam parados em casa e não sabiam onde descartar.

\section{O Reaproveitamento de lixo eletrônico}

Foram produzidas 50 unidades de BioTv's com a participação dos estudantes, que foram direcionadas para diversas instituições, permitindo a ampliação do projeto. De acordo com Fugimoto et al. (2014), a confecção dos aquários utilizando pisos cerâmicos é considerada relativamente fácil, sendo o principal cuidado a ser tomado, é em relação a vedação de todas as partes do aquário para que não haja vazamentos no mesmo. Devido ao baixo custo da produção, propiciando a reciclagem e a reutilização de alguns matérias a tem se tornado uma alternativa para pequenos produtores. Dessa forma diversas unidades de BioTv interativa foram produzidas com o lixo eletrônico e restos de pisos cerâmicos tornando o trabalho viável e satisfatório (Figura 5.)
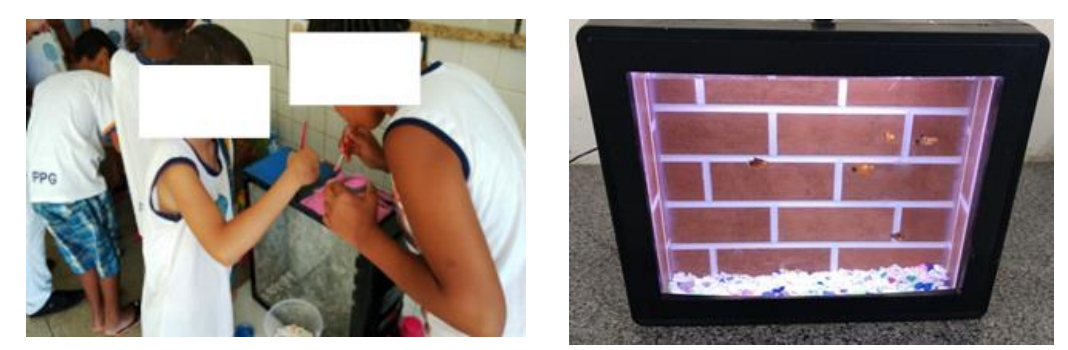

Figura 5: Ornamentação dos estudantes na fase final de produção da BioTv Interativa.

Fonte: Elaborado pelos autores

A esse respeito, Correia (2001, apud FELIX, 2007) afirma que é por meio de ações e práticas sustentáveis, que buscam a conservação e preservação do meio ambiente, de forma a inserir a comunidade nesse processo, demonstrando que a utilização dessas atitudes de proteção ao meio ambiente resulta em diversos benefícios tanto próprio como comunitário, e ainda contribuir para o desenvolvimento de pessoas comprometidas com a sustentabilidade do planeta. Destacando assim a importância da redução, da reutilização e da reciclagem do lixo para a natureza, e os prejuízos causados pelo acúmulo desses materiais para a saúde pública.

Após a produção dos aquários sustentáveis, diversas maneiras de ornamentação foram realizadas para dar mais vida ao ecossistema ali formado, sendo utilizadas conchas do mar, pedras para aquários, papel de parede, lâmpadas de led, buscando aperfeiçoar a estética dos aquários confeccionados.

Com a implantação do trabalho, tornou-se possível ampliar a relação do Ifes - Campus de Alegre com outros setores da sociedade como: Escolas Municipais, Secretarias Municipais de Educação, proporcionando uma 
interação social. Além de promover a inclusão e a valorização dos alunos das escolas de rede municipal, contribuindo para o processo de ensino $x$ aprendizagem em espaços de educação não formal, proporcionando a construção de um conhecimento mútuo dos participantes, impactando na formação dos estudantes e ampliando a sua capacidade de comunicação.

A sustentabilidade norteou as etapas realizadas no trabalho, uma vez que esta abrange as questões relacionadas à degradação e poluição ambiental, reciclagem e reutilização da maior parte dos materiais usados na produção dos aquários sendo um dos desafios a serem cumprido. Dentre as 50 unidades de lixo eletrônico coletados, 30 delas foram transformadas em aquários sustentáveis, denominadas BioTv Interativa. Sendo destinadas às escolas municipais e instituições parceiras do trabalho, além de serem apresentadas em exposições e feiras. Os demais equipamentos não foram produzidos devido as limitações financeiras e o fato de o trabalho não receber nenhum recurso financeiro para a sua continuidade.

Dentre as ações de Educação Ambiental desenvolvidas no trabalho pode-se destacar o plantio de espécies nativas no município de Jerônimo Monteiro, realizado no dia mundial da água, onde os alunos do $5^{\circ}$ ano do período matutino da escola municipal, participaram da ação de reflorestamento e recuperação da nascente dentro da propriedade e ainda conheceram o sistema de tratamento de esgoto realizado através de fossa séptica biodigestora que o proprietário construiu para o tratamento do esgoto rural. A Figura 6, demonstra essa ação realizada com a finalidade do plantio de espécies nativas para recuperação de nascentes.

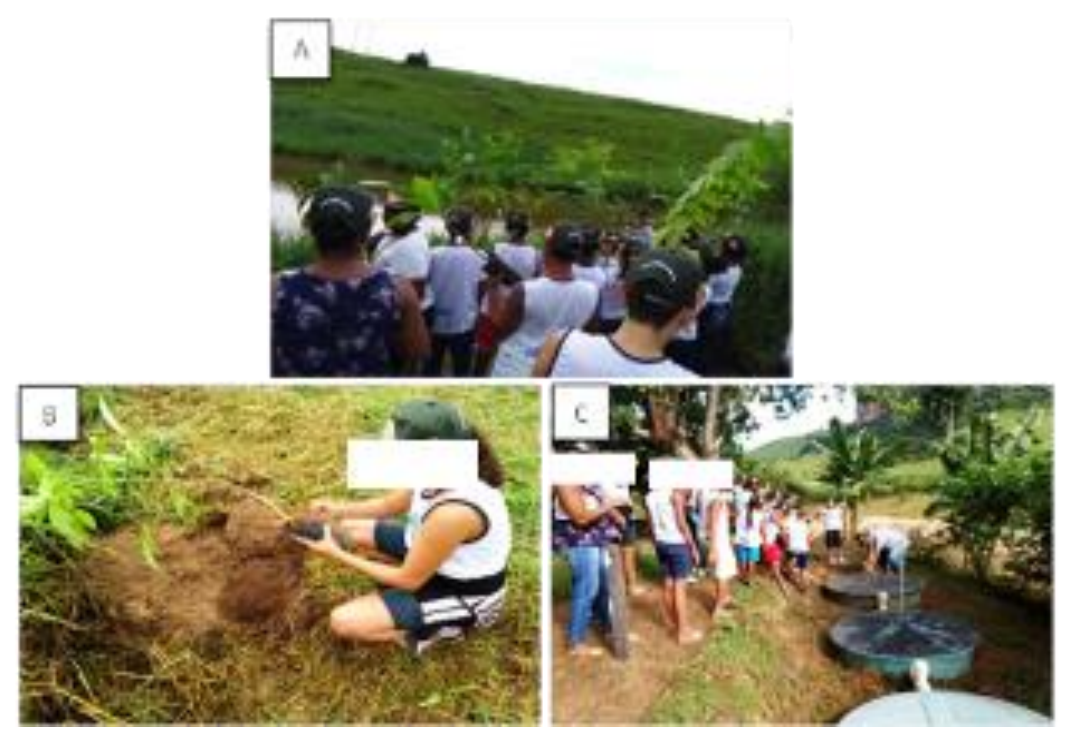

Figura 6: A - Visita as margens da nascente com ausência de mata ciliar, B - Plantio de espécies de nativas para recuperação de mata ciliar, C - Conhecendo o sistema de fossa biodigestor. Fonte: Elaborado pelos autores 
A BioTv interativa tem ainda intuito de produzir uma cartilha interdisciplinar com questões de língua portuguesa e matemática, voltadas aos recursos hídricos, poluição, organismos aquáticos entre outras, as quais vem sendo desenvolvidas no decorrer do trabalho com o intuito de produzir um material didático interdisciplinar que auxilie professores do ensino fundamental.

\section{Considerações finais}

Foi possível concluir que é viável a utilização de lixo eletrônico e de pisos cerâmicos para a produção de aquários sustentáveis, uma vez que os aquários produzidos prezaram pela qualidade e não apresentaram vazamento, passando pelo teste de vedação, obtendo firmeza em todas as partes, além de ter uma excelente aprovação do público-alvo e externo. Sendo assim fica evidente que a BioTv interativa despertou nos alunos e em toda a comunidade, importantes atitudes e ações ambientais responsáveis, através das ações realizadas no trabalho.

Partindo do âmbito da sustentabilidade ambiental, conclui-se ainda que a BioTv Interativa de acordo com o método de observação direta é considerada como uma ferramenta de Educação Ambiental não formal, contribuindo para o desenvolvimento de uma sociedade mais sustentável, possibilitando a troca de informações e experiências através de práticas que intensificam e focam a troca de conhecimentos, contribuindo para uma interação saudável e consciente de todos os integrantes, além de fomentar a noção de pertencimento na natureza.

\section{Referências}

ALCON PET. Seu novo Aquário, fazendo certo desde o início. 2018. Disponível em: <http://alconpet.com.br/download/guias/guia-seu-novoaquario.pdf $>$. Acesso em 08 nov 2018.

ALMEIDA, M.A.; PAPANDREA, P.J.; CARNEVALI, M.; ANDRADE, A.X.; CORREA, F.P.V.; ANDRADE, M.R.M. Destinação do Lixo Eletrônico: Impactos Ambientais causados pelos resíduos Tecnológicos. Revista Científica eLocução, v. 1, n. 7, p. 56, 2015.

ASANO, J.G. P; POLETTO, R.S. Educação Ambiental: Em busca de uma sociedade sustentável, e os desafios enfrentados nas escolas. Caderno pedagógico, Lajeado, v. 14, n. 1, p. 92-102, 2017.

BALDÉ, C.P., FORTI V., GRAY, V., KUEHR, R., STEGMANN, P: The Global E-waste monitor - 2017, United Nations University (UNU), International Telecommunication Union (ITU) \& International Solid Waste Association (ISWA), Bonn/Geneva/Vienna.2017.

BRASIL. Lei no 6.938, de 31 de agosto de 1981.

BRASIL. Lei $\mathbf{n}^{\circ}$ 9.795, de 27 de abril de 1999. 
BRASIL. Lei no 12.305, de 2 de agosto de 2010.

CORRADINI, M. S. Montagem e manutenção de um aquário marinho para a manutenção de invertebrados com fins didáticos. Relatório final apresentado ao Programa de Incentivo à Iniciação Científica. São Paulo: Centro Universitário Fundação Santo André, 2007.

FELIX, R.A. Z. Coleta seletiva em ambiente escolar. Rev. Eletrônica Mestr. Educ. Ambient. v.18, janeiro a junho de 2007.

FUJIMOTO, Y.R; SANTOS, R.F.B; FIGUEIREDO JUNIOR, A.M. Uso de Material Alternativo para Construção de Aquários e Filtros para Criação de Peixes. Embrapa Tabuleiros Costeiros. Comunicado Técnico, 143. Aracaju, dez. 2014.

GAMA, E.F; VASCONCELOS, J.M.S; MACHADO, A.L.S. logística reversa do lixo eletrônico: Um estudo de caso no instituto federal do amazonas - campus Manaus distrito industrial. Revista de Extensão do IFAM Vol.2 | №2 | dez. 2016. Manaus,2016.

GADOTTI, M. Educação Popular, Educação Social, Educação Comunitária: conceitos e práticas diversas, cimentadas por uma causa comum, p. 10-32. Revista Diálogos: Pesquisa em extensão universitária. IV Congresso Internacional de Pedagogia Social: domínio epistemológico. Brasília, v.18, n.1, dez, 2012.

GOHN, MARIA DA GLÓRIA. Educação não formal e o educador social: Atuação no Desenvolvimento de Projetos Sociais. São Paulo: Cortez, 2010.

JACOBI, Pedro. Educação Ambiental, cidadania e sustentabilidade. Cadernos de Pesquisa, n. 118, p. 189-205, março/ 2003.

LAKATOS, E. MARCONI, M. Fundamentos de Metodologia Científica. São Paulo: Atlas, 1992.

MATAREZI, JOSÉ. Despertando os sentidos da Educação Ambiental. Educar, Curitiba, n. 27, p. 181-199, 2006. Editora UFPR.

MATTAR, M. E. Lixo eletrônico um problema que não se deleta. Ciência y Tecnologia. Rets. Brasil, mar. 2002.

MATTOS, K.M.C.; PERALES, W.J.S. Os impactos ambientais causados pelo lixo eletrônico e o uso da logística reversa para minimizar os efeitos causados ao meio ambiente. Anais... Encontro Nacional de Engenharia de Produção, v. 28, 2008. Rio de Janeiro: ENEP, 2008. p. 2 - 11.

MENDONÇA, S. G. L.; SILVA, P.S. Extensão Universitária: Uma nova relação com a administração pública. Extensão Universitária: ação comunitária em universidades brasileiras. São Paulo, v. 3, p. 29-44, 2002.

MENEZES, T. A.; MENDONÇA, C. M. L. A.; ARAGÃO, U. S. A utilização de aquários e terrários como ferramenta de ensino: um olhar pelo viés da experimentação. In: Seminário de Iniciação Científica (SEMIC). Anais... Universidade Estadual de Feira de Santana/BA. UEFS, 2011.

Revbea, V. 14, № 3: 325-343, 2019. 
MOREIRA, E.C. Logística reversa do lixo tecnológico: O cenário nas empresas brasileiras. Anais do Encontro Internacional sobre gestão empresarial e meio ambiente. São Paulo, 2014.

MUCELIN, C.A; BELLINI, M. Lixo e impactos ambientais perceptíveis no ecossistema urbano. Sociedade \& Natureza, Uberlândia, 20 (1): 111-124, jun. 2008.

NATUME, R. Y.; SANT'ANNA, F. S. P. Resíduos eletroeletrônicos: um desafio para o desenvolvimento sustentável e a nova Lei da política nacional de resíduos sólidos. Anais ... III International Workshop on Advances in Cleaner Production. São Paulo: CPICSW, 2011.

OLIVEIRA, C.C.; CHAGAS, J.R.; TEIXEIRA, P.M.M. A utilização de aquário como recurso didático para o ensino de Ciências em uma escola pública de Jequié/BA. Anais do IX Encontro Nacional de Pesquisa em Educação em Ciências - IX ENPEC, Águas de Lindóia, SP, 2013.

PROCHNOW, T. R; ROSSETTI, J. Resíduos Sólidos: Coleta seletiva e Educação Ambiental na cidade de Esteio - RS, Brasil. Ambiente \& Educação | vol. 15(2) | 2010.

SALES, K.O; DIAS F.K.D. O lixo tecnológico como ferramenta didático/pedagógica para o ensino fundamental. Geosaberes, Fortaleza, v. 4, n. 8, p. 67-78, jul./ dez. 2013.

SILVA, J.R.N. Lixo eletrônico: Um estudo de responsabilidade ambiental no contexto do instituto de educação ciência e tecnologia do amazonas - Ifam campus Manaus centro. In Anais... I Congresso Brasileiro de Gestão Ambiental. Baurú, São Paulo, 2010. Disponível em: <http://www.webresol.org/textos/iii-009.pdf> Acesso em: 03 set de 2018.

TANAUE, A.C.B; BEZERRA, D.M; CAVALHEIRO, L; PISANO, L.C. Lixo Eletrônico: Agravos a Saúde e ao Meio Ambiente. Ensaios Cienc., Cienc. Biol. Agrar. Saúde, v.19, n.3, p. 130-134, 2015.

VALENTIM, G. H.; MALAGOLLI. G. A. Uma abordagem sobre a reciclagem em aparelhos eletrônicos. 2015. Anais eletrônicos ... III SIMTEC - Simpósio de Tecnologia da FATEC Taquaritinga. 